\title{
Concrete quality on-site vs separately manufactured specimens
}

\author{
Frank Jacobs \\ TFB AG, Lindenstrasse 10, 5103 Wildegg, Switzerland
}

\begin{abstract}
In most cases insufficient durability is the reason for concrete damages and not insufficient strength. Therefore, the Swiss concrete standard SN EN 206 set up requirements on the concrete composition and the testing of separately manufactured concrete samples. It is well known that the properties of concrete in structural members can deviate from that determined on separately manufactured samples. A research project was launched to determine this difference. Based on the results an appropriate testing regime should be proposed and the limiting values for the durability properties should be verified.
\end{abstract}

\section{Introduction}

When the European concrete standard EN 206-1 was introduced in Switzerland 2003, requirements on the concrete composition were set up depending on the exposure class. Additionally, the concrete plants were obliged to perform tests on separately manufactured concrete samples for selected durability properties. Within a research project the results were evaluated (Jacobs \& Leemann). It could be shown that neither limitations on the composition (e.g. Fig. 1) are sufficient to obtain the required durability properties nor that durability properties can be reasonably predicted from other properties (e.g. strength, Fig. 2). For instance: To achieve for most of the concrete mixes a chloride migration coefficient of $\leq 10 \times 10^{-12} \mathrm{~m}^{2} / \mathrm{s}$ the w/c ratio should be less than 0.40 (Fig. 1) or the mean cube compressive should be higher than $70 \mathrm{MPa}$ (fig. 2). Both requirements would exclude many suitable concrete mixes.

Based on these finding limiting values for durability properties were introduced in a new edition of the Swiss concrete standard SN EN 206-1. The requirements in the newest edition of the concrete standard (SN EN 206), depending on the type of concrete (exposure class), are shown in Tab. 1 for durability tests and in Tab. 2 for limiting values (Tab. 2).

In the durability tests the chloride migration coefficient is determined according to SIA 262/1 by applying a voltage of $20 \mathrm{~V}$ during 24 hours on three or five cores (depends on maximum aggregate size and 50 $\mathrm{mm}$ or $100 \mathrm{~mm}$ core diameter) taken from separately manufactured specimens (test regime TT-1 with testing age 28 days) or from the structural members itself (test regime TT-2 with testing age 28 days or TT-3 with higher testing ages). The uptake of the $\mathrm{NaCl}$ solution takes place from the side of the moulded surface, after the outmost 5 to $10 \mathrm{~mm}$ are cut off. The higher the chloride migration coefficient the lower the resistance to chloride ingress.

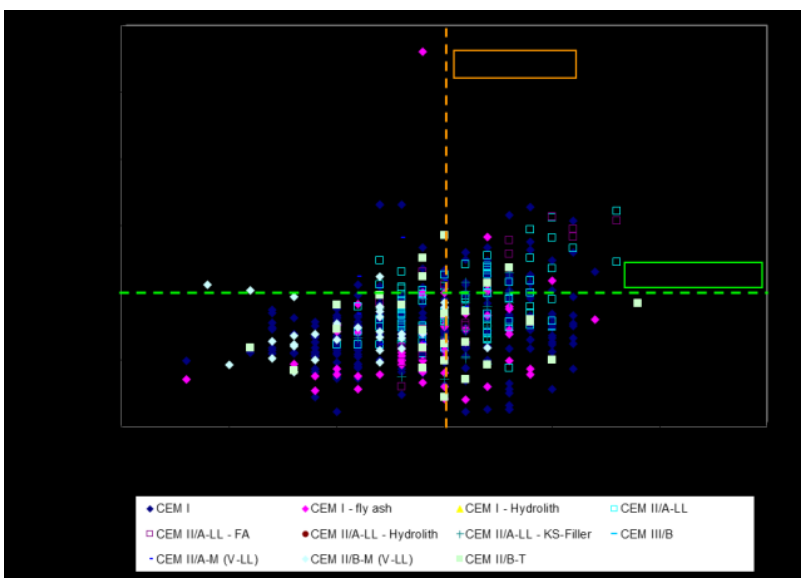

Fig. 1. Relationship between w/c-ratio and chloride migration coefficient, determined on separately manufactured samples from more than 80 concrete plants, from Jacobs \& Leemann [1]

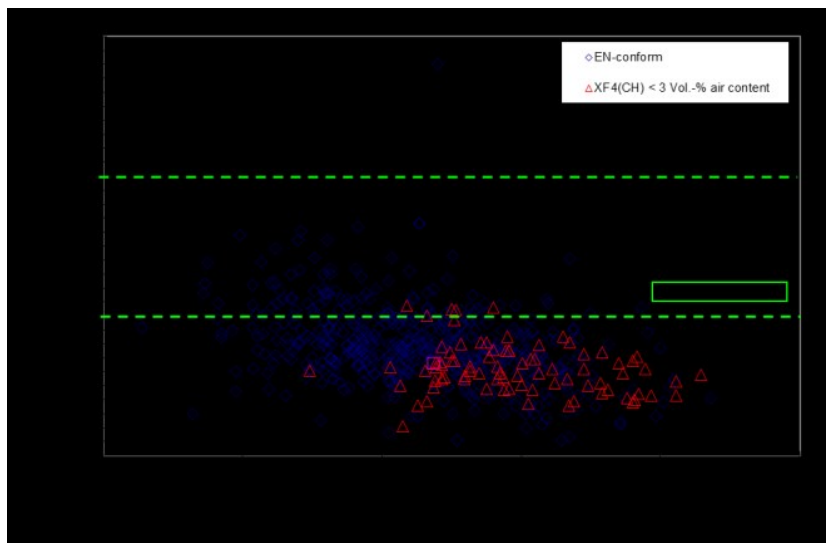

Fig. 2. Relationship between mean cube compressive strength and chloride migration coefficient, determined on separately manufactured samples from more than 80 concrete plants [1] 
Table 1. Concrete type, exposure classes and requirements on concrete composition for maximum aggregate size $32 \mathrm{~mm}$ and durability testing; WL: water conductivity; KW: carbonation test, CW: chloride migration test, FT: freeze-thaw with deicing salt test.

\begin{tabular}{|c|c|c|c|c|c|c|c|c|}
\hline $\begin{array}{l}\text { concrete } \\
\text { type }\end{array}$ & 0 & $\mathrm{~A}$ & B & $\mathrm{C}$ & $\mathrm{D}$ & $\mathrm{E}$ & $\mathrm{F}$ & $\mathrm{G}$ \\
\hline $\begin{array}{l}\text { exposure } \\
\text { class }\end{array}$ & $\mathrm{X} 0$ & $\mathrm{XC2}$ & $\mathrm{XC3}$ & $\begin{array}{l}\mathrm{XC} 4 \\
\mathrm{XF} 1\end{array}$ & $\begin{array}{l}\mathrm{XC4} \\
\mathrm{XD1} \\
\mathrm{XF2}\end{array}$ & $\begin{array}{l}\mathrm{XC4} \\
\mathrm{XD} 1 \\
\mathrm{XF} 4\end{array}$ & $\begin{array}{l}\mathrm{XC4} \\
\mathrm{XD} 3 \\
\mathrm{XF} 2\end{array}$ & $\begin{array}{l}\mathrm{XC4} \\
\mathrm{XD} 3 \\
\mathrm{XF} 4\end{array}$ \\
\hline $\max . w / c$ & - & 0.65 & 0.60 & \multicolumn{3}{|c|}{0.50} & \multicolumn{2}{|c|}{0.45} \\
\hline $\begin{array}{l}\text { min. } \\
\text { cement } \\
\text { content }\end{array}$ & - & \multicolumn{2}{|c|}{$280 \mathrm{~kg} / \mathrm{m}^{3}$} & \multicolumn{3}{|c|}{$300 \mathrm{~kg} / \mathrm{m}^{3}$} & \multicolumn{2}{|c|}{$320 \mathrm{~kg} / \mathrm{m}^{3}$} \\
\hline $\begin{array}{l}\text { durability } \\
\text { test }\end{array}$ & \multicolumn{2}{|c|}{ none } & $\begin{array}{l}\text { WL, } \\
\text { KW }\end{array}$ & KW & \multicolumn{2}{|c|}{ KW, FT } & \multicolumn{2}{|c|}{$\mathrm{CW}, \mathrm{FT}$} \\
\hline $\begin{array}{l}\text { allowed } \\
\text { type of } \\
\text { cement }\end{array}$ & \multicolumn{8}{|c|}{$\begin{array}{c}\text { see Table NA.1; for combinations of exposure class the most severe } \\
\text { requirement must be applied }\end{array}$} \\
\hline
\end{tabular}

Table 2. Durability testing and limiting and guidance values for various concrete types and exposure classes, extract from SN EN 206 and SIA 262/1

\begin{tabular}{|c|c|c|c|c|c|}
\hline & $\begin{array}{c}\text { water } \\
\text { conductivity } \\
\text { WL }\end{array}$ & $\begin{array}{c}\text { carbonation } \\
\text { resistance } \\
\text { KW }\end{array}$ & $\begin{array}{l}\text { chloride } \\
\text { migration } \\
\text { coefficient }\end{array}$ & \multicolumn{2}{|c|}{$\begin{array}{c}\text { freeze-thaw with } \\
\text { de-icing salt } \\
\text { resistance }\end{array}$} \\
\hline $\begin{array}{l}\text { test acc. SIA } \\
262 / 1\end{array}$ & annex A & annex I & annex B & \multicolumn{2}{|c|}{ annex $\mathrm{C}$} \\
\hline $\begin{array}{l}\text { required for } \\
\text { exposure } \\
\text { class }\end{array}$ & $\mathrm{XC} 3$ & $\begin{array}{c}\mathrm{XC3}, \mathrm{XC4}, \\
\text { XD1, } \\
\text { XD2a, XF1 }\end{array}$ & $\begin{array}{l}\text { XD2b, } \\
\text { XD3 }\end{array}$ & $\begin{array}{c}\text { XF2, } \\
\text { XGF3 }\end{array}$ & XF4 \\
\hline $\begin{array}{l}\text { required for } \\
\text { concrete } \\
\text { type }\end{array}$ & $\mathrm{B}$ & $\mathrm{B}, \mathrm{C}, \mathrm{D}, \mathrm{E}$ & $\mathrm{F}, \mathrm{G}$ & $\mathrm{D}, \mathrm{F}$ & $\mathrm{E}, \mathrm{G}$ \\
\hline $\begin{array}{l}\text { limiting } \\
\text { value for } \\
\text { TT-1 }\end{array}$ & $10 \mathrm{~g} / \mathrm{m}^{2} \mathrm{~h}$ & $5.0 \mathrm{~mm} / \sqrt{\mathrm{a}}$ & $\begin{array}{c}10 \times 10^{-12} \\
\mathrm{~m}^{2} / \mathrm{s}\end{array}$ & $\begin{array}{l}2500 \\
\mathrm{~g} / \mathrm{m}^{2}\end{array}$ & $\begin{array}{c}200 / \\
600 \\
\mathrm{~g} / \mathrm{m}^{2}\end{array}$ \\
\hline $\begin{array}{l}\text { limiting val- } \\
\text { ue }+ \text { devia- } \\
\text { tion for TT-1 }\end{array}$ & $12 \mathrm{~g} / \mathrm{m}^{2} \mathrm{~h}$ & $5.5 \mathrm{~mm} / \sqrt{\mathrm{a}}$ & $\begin{array}{c}13 \times 10^{-12} \\
\mathrm{~m}^{2} / \mathrm{s}\end{array}$ & $\begin{array}{l}3000 \\
\mathrm{~g} / \mathrm{m}^{2}\end{array}$ & $\begin{array}{c}250 / \\
800 \\
\mathrm{~g} / \mathrm{m}^{2}\end{array}$ \\
\hline $\begin{array}{l}\text { minimum } \\
\text { testing } \\
\text { frequency } \\
\text { for } \\
\text { experienced } \\
\text { manufacturer }\end{array}$ & \multicolumn{2}{|c|}{$\begin{array}{c}\text { min. } 4 \mathrm{x} / \text { year or } \\
\text { every } 500 \mathrm{~m}^{3} \\
>4000 \mathrm{~m}^{3} \text { every } 1000 \mathrm{~m}^{3} \\
>17000 \mathrm{~m}^{3} \text { every } 1250 \mathrm{~m}^{3} \\
>30000 \mathrm{~m}^{3} \text { every } 1500 \mathrm{~m}^{3} \\
>60000 \mathrm{~m}^{3} \text { every } 3000 \mathrm{~m}^{3}\end{array}$} & \multicolumn{3}{|c|}{$\begin{array}{c}\text { min. } 4 \mathrm{x} / \text { year or } \\
\text { every } 125 \mathrm{~m}^{3} \\
>1000 \mathrm{~m}^{3} \text { every } 250 \mathrm{~m}^{3} \\
>2000 \mathrm{~m}^{3} \text { every } 500 \mathrm{~m}^{3}\end{array}$} \\
\hline $\begin{array}{l}\text { guidance } \\
\text { values for } \\
\text { TT-2 }\end{array}$ & $12 \mathrm{~g} / \mathrm{m}^{2} \mathrm{~h}$ & $5.3 \mathrm{~mm} / \sqrt{ } \mathrm{a}$ & $\begin{array}{l}12 \times 10^{-} \\
12 \mathrm{~m}^{2} / \mathrm{s}\end{array}$ & $\begin{array}{l}3000 \\
\mathrm{~g} / \mathrm{m}^{2}\end{array}$ & $\begin{array}{l}300 / \\
800 \\
\mathrm{~g} / \mathrm{m}^{2}\end{array}$ \\
\hline
\end{tabular}

The carbonation coefficient according to SIA 262/1 should be determined on prims $120 \times 120 \times 360 \mathrm{~mm}^{3}$ (test regime TT-1 with testing age 28 days) or on four cores with $50 \mathrm{~mm}$ diameter taken from the structural members (test regime TT-2 with testing age 28 days or TT-3 with higher testing ages) according to SIA 262/1. After a defined preconditioning of the specimens they are subjected to $4 \% \mathrm{CO}_{2}$ and $57 \%$ r.h. for 63 days. From the depths of carbonation, determined after 7, 28 und 63 days and predefined conversion values the carbonation coefficient is calculated for usual environmental conditions with $0.04 \% \mathrm{CO}_{2}$. The higher the carbonation coefficient the lower the resistance to $\mathrm{CO}_{2}$ ingress.

The freeze-thaw resistance with de-icing salt should be determined according to SIA $262 / 1$ on separately manufactured specimens at 28 days (testing regime TT1) or from cores taken from the structural members and tested at 28 days (testing regime TT-2) or tested at higher ages (testing regime TT-3). The specimens underwent 28 cycles between -15 and $+15{ }^{\circ} \mathrm{C}$ during 14 days.
The capillary water uptake is determined on cores from separately manufactured specimens or on cores from the structure according to SIA 262/1. They are immersed on one side $3 \mathrm{~mm}$ (after the outmost 5 to 10 $\mathrm{mm}$ are cut off) in water for 24 hours. From the water uptake and some predefined assumptions, a water conductivity value is calculated.

Until now it is up to the testing laboratory, if the specimens for chloride migration, water conductivity testing and freeze-thaw resistance testing with de-icing salts are stored after the demoulding at $20{ }^{\circ} \mathrm{C}$ under water or in air with $\geq 95 \%$ r.h. It was found that the storage condition could has a large influence on the results and that its influence was diverging. Therefore, in the new issue of the standard SIA 262/1 only a storage under water is allowed, because this storage is much easier achievable than a storage at $\geq 95 \%$ r.h. in the whole storage facility.

\section{Research Project}

\subsection{Background}

It is well known that the concrete strength in structural members deviates from that determined on separately manufactured specimens, e.g. cubes. In the standard SN EN 13791 the compressive strength, determined on cores, must be at least $85 \%$ of the required strength class. For durability properties the difference between cores from the structure and separately manufactured specimens is hardly known. A few exceptions exist, e.g. Gouws et al. [3]. The Swiss road authorities funded in the years 2015 - 2018 a project to determine the durability differences between separately manufactured specimens and structural members [4]. Six construction sites (Gn, Ma, Po, Gr, Ep, Ha) were selected where the concrete types $\mathrm{F}$ and $\mathrm{G}$ (see Tab. 1) were used.

On each construction site the manufacture of four structural members was accompanied. This means that fresh concrete testing (SN EN 12350, SIA 262/1) including the manufacture of specimens and their testing at 28 days was performed. Approximately three weeks after the manufacture of the structural members cores were drilled and tested at 28 days, too. The tests comprised the density (SN EN 12350-6, SN EN 123907), the compressive strength (SN EN 12504-1), the chloride migration (SIA 262/1) and the freeze-thaw resistance with de-icing salts (SIA 262/1). Partly, the carbonation coefficient (SIA 262/1) was determined, too. Each point in the subsequent figures represents the mean of 3 - 5 specimens (number according to the requirements in the standards).

Several tests on one construction site were made because it was shown that the environmental conditions can significantly influences the concrete properties (Jacobs et al.) In Fig. 3 results for the chloride migration test are shown for concrete $(\mathrm{w} / \mathrm{c}=0.45)$ with cement CEM III/B (containing approx. $70 \%$ ground blast furnace slag) and storage temperatures of $20{ }^{\circ} \mathrm{C}$ and 6 ${ }^{\circ} \mathrm{C}$. The longer the curing (water storage, wrapped in plastic) at $20{ }^{\circ} \mathrm{C}$ lasted, the lower was the chloride 
migration coefficient determined at 28 days. The applied curing compound (paraffin wax) and the controlled permeable formwork for de-watering the concrete surface, both during storage at $20{ }^{\circ} \mathrm{C}$, were very efficient and comparable to that of 28 days water storage. For water cured concrete the difference between testing the original cast surface (denoted oR in the Fig. 3) or after cutting of $5-10 \mathrm{~mm}$ was mostly negligible. The storage at $6{ }^{\circ} \mathrm{C}$ lead in general to much better concrete properties than storage at $20^{\circ} \mathrm{C}$, even for very short curing periods.
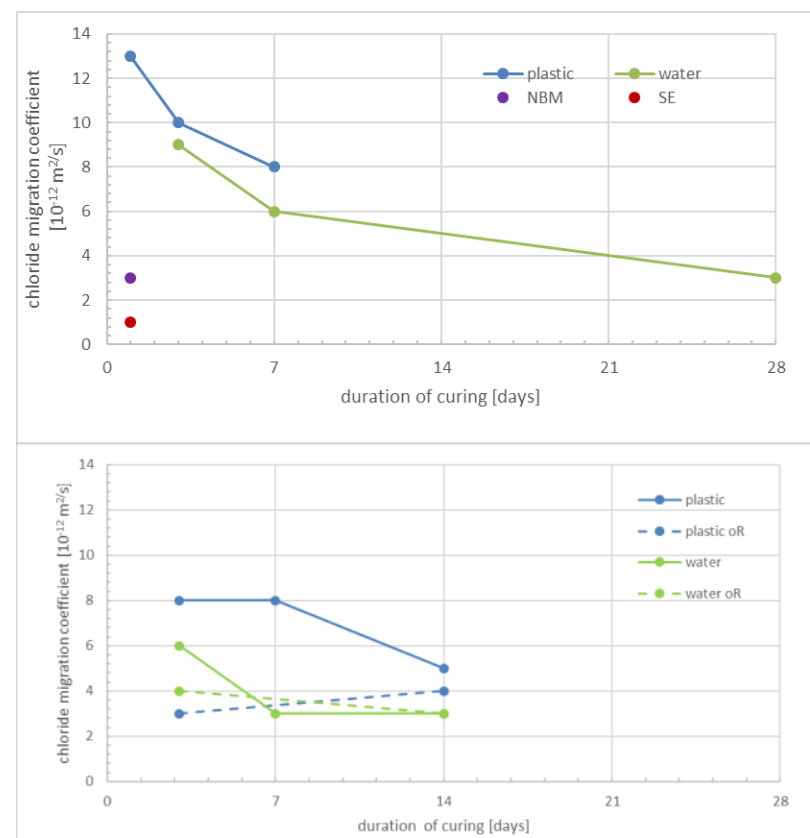

Fig. 3. Chloride migration coefficient of concrete with CEM IIII/B stored at $20{ }^{\circ} \mathrm{C}$ (above) and $6{ }^{\circ} \mathrm{C}$ (below) for several curing regimes and lengths; test according to the standard without and with cutting of the outmost $5-10 \mathrm{~mm}(\mathrm{oR})$; NBM: curing compound used after demoulding, no further curing; SE: controlled permeable formwork to de-water concrete surface, no further curing after demoulding

The new tests were arranged in such a way that on each construction site structural members of very similar geometry could be tested, because the geometry (e.g. wall, column, slab) influences concrete quality. It was controlled that all structural members were properly cured according to the Swiss standard SIA 262 (Tab. 3). The curing classes 3 or 4 should be applied for moderately weathered surfaces (XC4, XF1) or intensely weathered surfaces (XD3, XF4). It was shown that the strength development is not a suitable indicator for the necessary curing duration to achieve sufficient durability properties. Especially for temperatures above $15{ }^{\circ} \mathrm{C}$ curing should last in minimum 7 days.

Table 3. Requirements for curing lengths (days), extract from SIA 262

\begin{tabular}{|l|l|c|c|c|c|}
\hline \multicolumn{2}{|l|}{ strength development $\mathrm{r}=\mathrm{fc}_{2} / \mathrm{fc}_{28}$} & \multicolumn{2}{|c|}{ rapid $\mathrm{r} \geq 0.50$} & \multicolumn{2}{c|}{ medium $0.50>\mathrm{r} \geq 0.30$} \\
\hline \multicolumn{2}{|c|}{ curing class } & 3 & 4 & 3 & 4 \\
\hline \multirow{2}{*}{$\begin{array}{l}\text { surface } \\
\text { temperature } \mathrm{T}\end{array}$} & $\geq 25^{\circ} \mathrm{C}$ & 1.5 & 3 & 2.5 & 5 \\
\cline { 2 - 6 } of concrete $\left[{ }^{\circ}\right]$ & $25>\mathrm{T} \geq 15$ & 2.0 & 5 & 4 & 9 \\
\cline { 2 - 6 } & $15>\mathrm{T} \geq 10$ & 2.5 & 7 & 7 & 13 \\
\cline { 2 - 6 } & $20>\mathrm{T} \geq 5$ & 3.5 & 9 & 9 & 18 \\
\hline
\end{tabular}

\subsection{Results}

In general, the density of the concrete in the separately manufactured cubes was approx. $2 \%$ higher than that determined on the fresh concrete (Fig. 4). The density of cores from the structural members was approx. $1 \%$ lower than the density of the cubes (Fig. 5). Partly a sitespecific behaviour could be observed. E.g. on the site Ma the density of the cores from the structural members was partly higher than that from separately manufactured cubes. The cores were taken approx. $0.5 \mathrm{~m}$ above the bottom of several meter-high walls. The dead weight of the concrete lead to an increased compaction. From different densities, different hardened concrete properties can be expected.

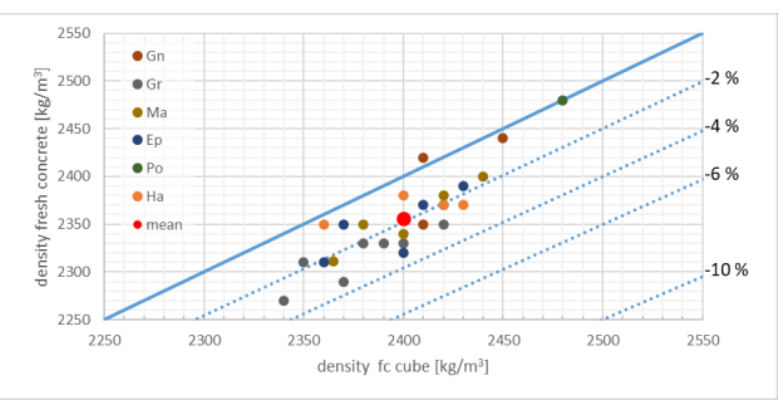

Fig. 4. Density, determined on the fresh concrete samples and cubes for compressive strength tests.

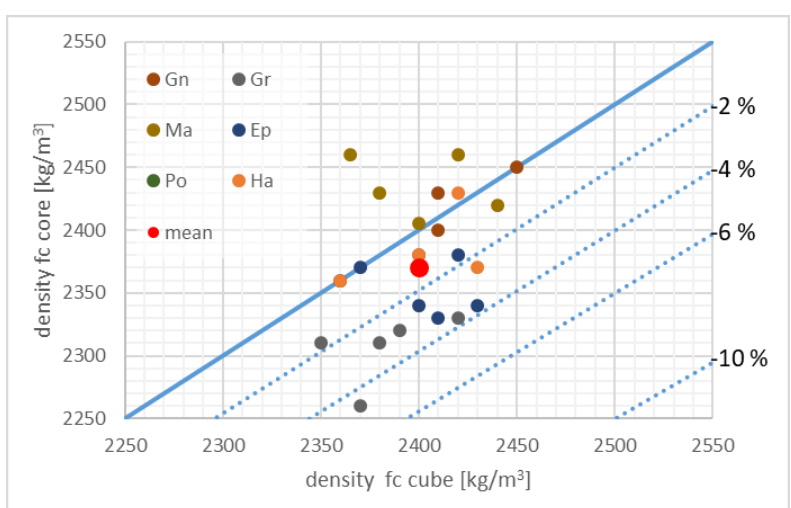

Fig. 5. Density, determined on the cores from the structural members and cubes for compressive strength tests.

In general, the compressive strength of cores from the structural members was approx. nearly $20 \%$ lower than the compressive strength of cubes (Fig. 6). Again, a site-specific behaviour could be observed (e.g. site Ma).

The same could be observed for durability properties. The chloride migration coefficient, determined on cores from the structural members was on average nearly $50 \%$ higher compared to separately manufactured cubes (Fig. 7). The freeze thaw resistance with de-icing salts showed not such a difference (Fig. 8). But the few results of the carbonation resistance showed a similar behaviour to the chloride migration coefficient (Fig. 9). 


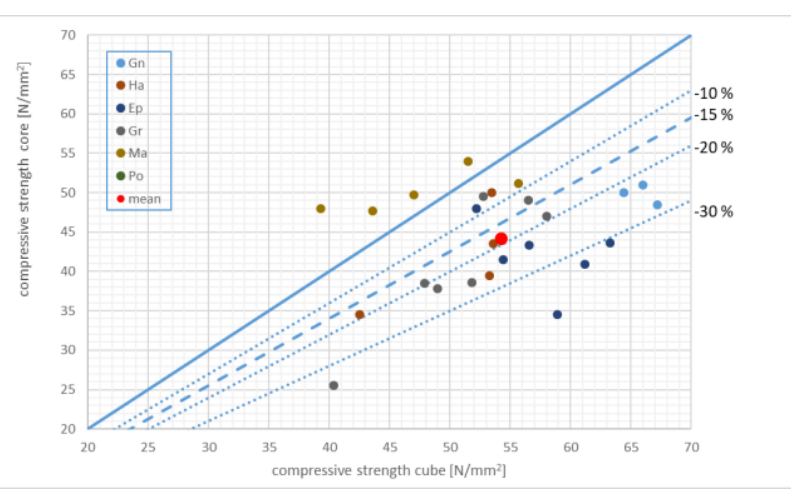

Fig. 6. Compressive strength, determined on the cores from the structural members and the cubes.

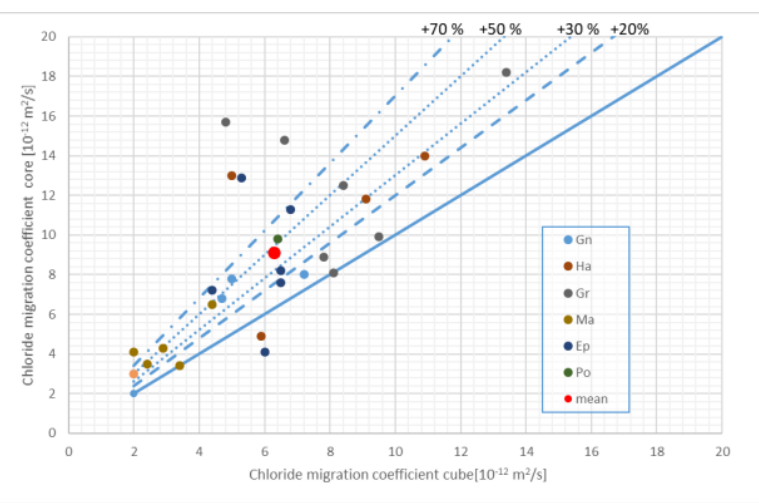

Fig. 7. Chloride migration coefficient, determined on the cores from the structural members and the cubes acc. to SIA 262/1.

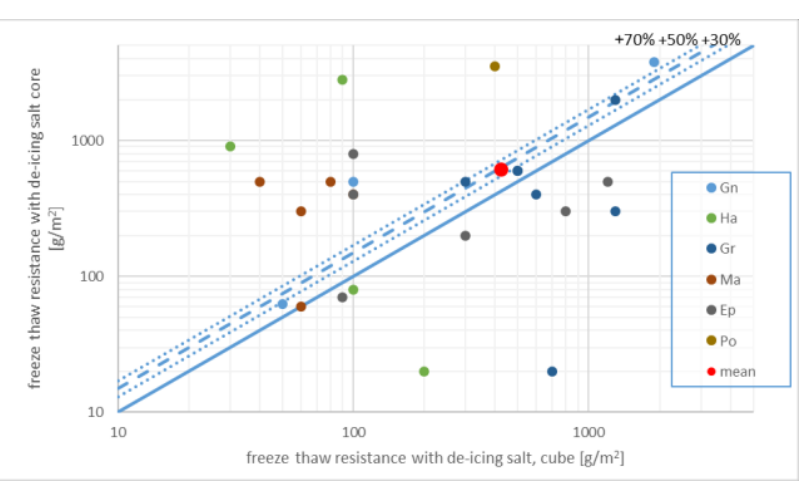

Fig. 8. Freeze thaw resistance with de-icing salts, determined on the cores from the structural members and the cubes acc. to SIA $262 / 1$.

The deviations between tested cores from the structural members and separately manufactured specimens can be attributed to the relevant (tested) concrete volume and concrete composition: The compressive strength is determined by the quality (density) of the whole specimen. The freeze-thaw resistance is strongly influenced by the outermost $1 / 10 \mathrm{~s}$ of $\mathrm{mm}$ of the concrete and hardly by variations in the total porosity (density). The chloride ingress and the carbonation progress depend strongly on the tightness (density) of the outermost $\mathrm{cm}$ of the specimens. Additionally, both properties can be strongly influenced by the type of cement. On the construction site Ma CEM II/A-S was used (cement with ground blast furnace slag) which decreases strongly the chloride migration coefficient.

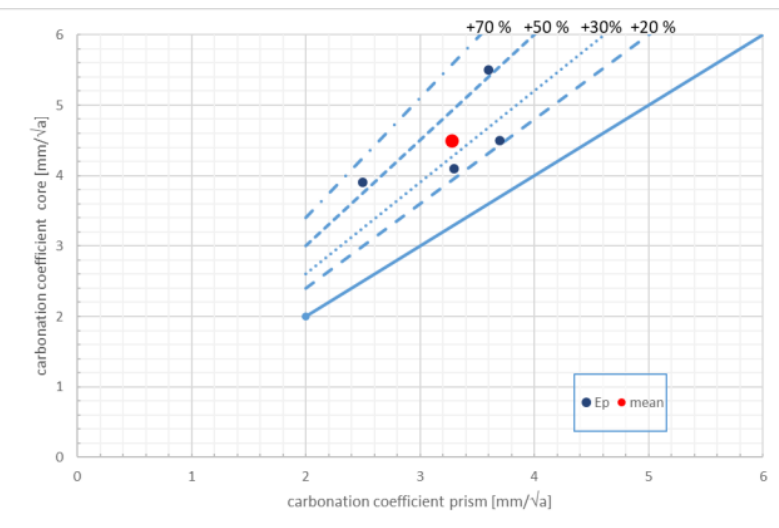

Fig. 9. Carbonation coefficient, determined on the cores from the structural members and prisms acc. to SIA 262/1.

To see if the site-specific workmanship and processes influence concrete quality, the coefficient of variation was calculated for all determined properties and sites. Based on the few results per site, no clear difference is obvious between sites among themselves and the properties determined on cores from the structural members or separately manufactured specimens (Fig. 10). The main reason for different coefficients of variation is the determined property (test procedure). Durability test have in general a higher scatter than e. g. compressive strength tests.

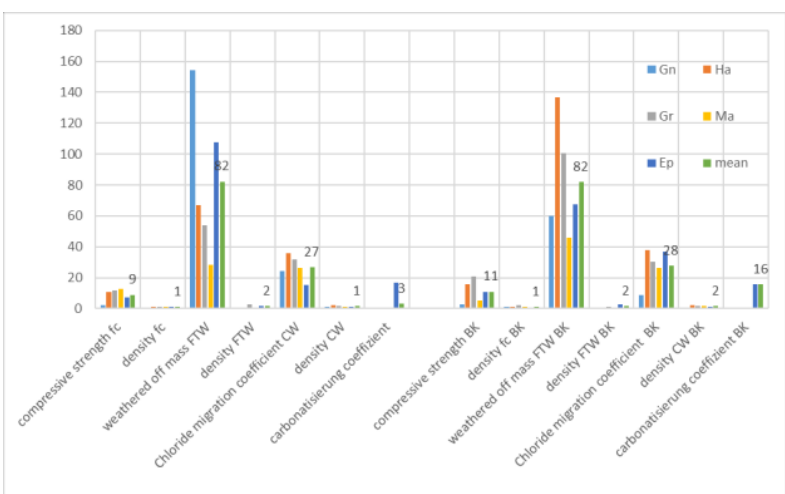

Fig. 10. Coefficient of variation of several site and properties. BK: cores taken from the structural members

At some sites it was possible to drill at later ages cores again. Due to the time limits of the research project, tests at a higher age could be performed only at approx. $3 / 4$ years. For all properties an improvement could be found (Fig. 11).

The destructive testing was accompanied by nondestructive testing using the rebound hammer acc. to SN EN 12504-1 and air permeability according to SIA 262/1. The rebound hammer gave only in some cases reliable indications for the core compressive strength. If the air permeability tested on site at a concrete age of 2 to 3 months was lower than $0.1 \times 10^{-16} \mathrm{~m}^{2}$, in most cases the limiting values for chloride migration and carbonation coefficient were fulfilled. 


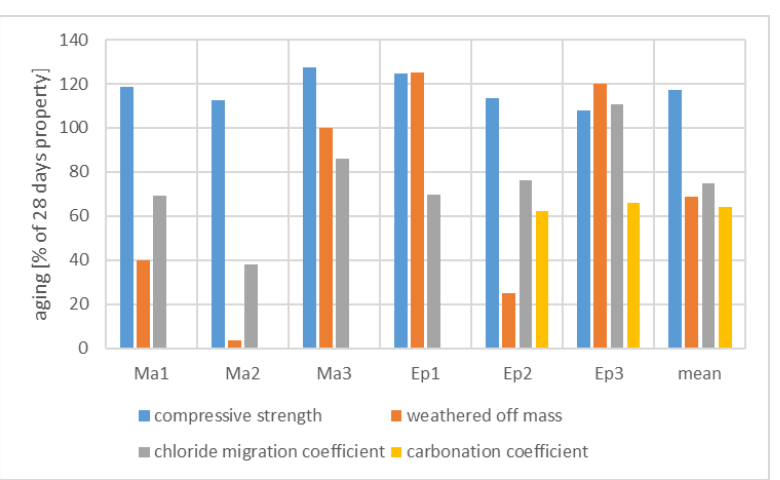

Fig. 11. Influence of concrete age on properties.

\section{Discussion}

To find out, if the air temperature has an influence on the concrete properties, the mean air temperature was calculated from the day of concreting until the day of drilling the cores. In some cases, a clear relationship between mean air temperature and core compressive strength was found (e.g. Gr slab, Fig. 12), in other cases no relationship exits (e.g. Gn). No durability property showed a clear relationship with the mean air temperature (see e.g. Fig 13). Between the chloride migration coefficient and the freeze thaw resistance with de-icing salts a relationship could be partly observed (Fig. 14). This was attributed to the influence of curing quality: An insufficient curing was performed. This means that although it was claimed that the curing was according to the standard (Tab. 3), the quality potential of the concrete was insufficiently developed.

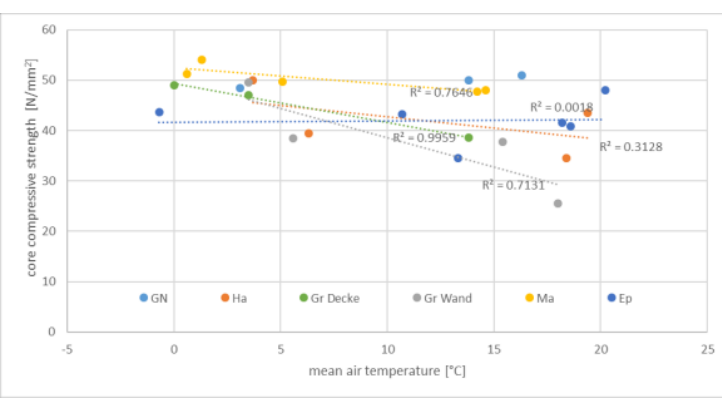

Fig. 12. Influence of mean air temperature on compressive strength, determined on cores from the structural members; Decke (slab), Wand (wall).

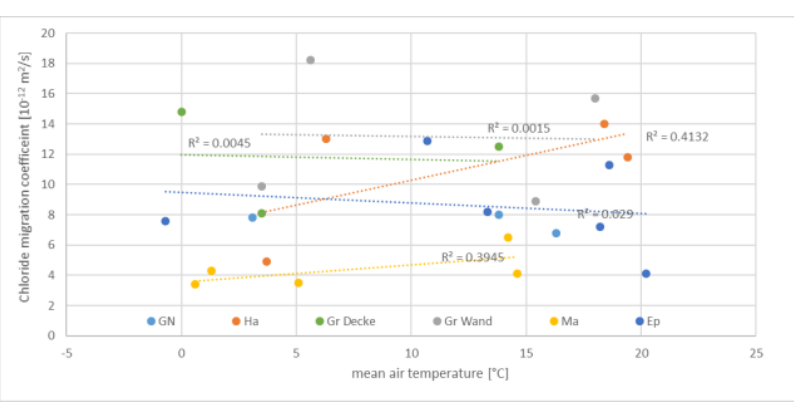

Fig. 13. Influence of mean air temperature on chloride migration coefficient, determined on cores from the structural members Decke (slab), Wand (wall).

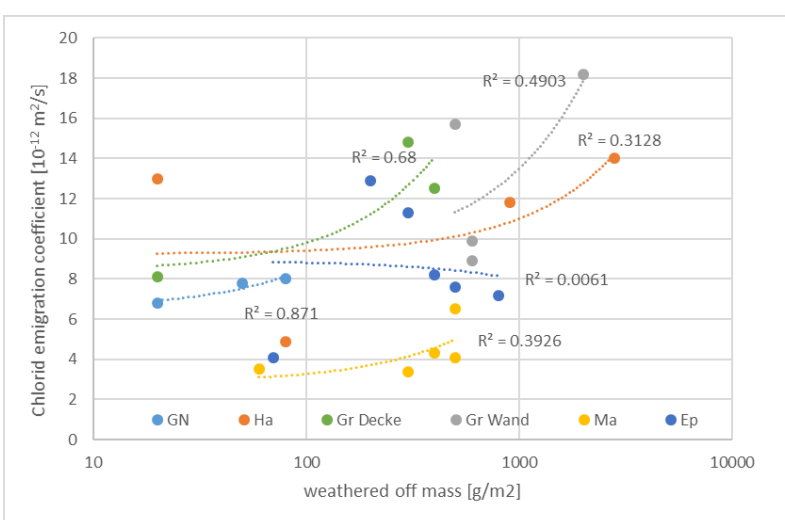

Fig. 14. Relationship between chloride migration coefficient and freeze thaw resistance with de-icing salts; Decke (slab), Wand (wall).

From the improvement of the concrete properties between 28 days and at approx. 3/4 years an aging factor was calculated by using the equation: $\mathrm{CM}_{28} / \mathrm{CM}_{\mathrm{n}}=$ $\left(\mathrm{t}_{28} / \mathrm{t}_{\mathrm{n}}\right)^{\mathrm{a}}$. For the chloride migration $(\mathrm{CM})$ and carbonation coefficient the aging factor was found to be between 0.1 and 0.2 (Fig. 15).

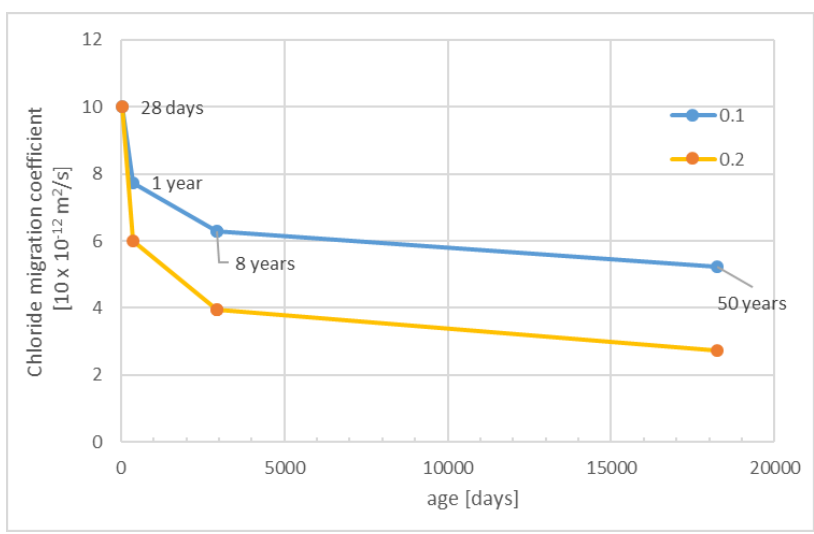

Fig. 15. Decrease in chloride migration coefficient for aging factors of 0.1 and 0.2 between 28 days and 50 years

\section{Conclusion}

Based on the results of the concrete tests, the following can be stated:

- The density of concrete in the structural member was generally $1-2 \%$ lower than that of the separately manufactured specimens.

- The compressive strength of the cores at 28 days was generally nearly $20 \%$ lower than that determined on separately manufactured cubes.

- The chloride migration coefficient, determined on cores, was generally nearly $50 \%$ higher than that determined on separately manufactured specimens.

- The freeze thaw resistance with de-icing salts, determined on cores, was generally like that determined on separately manufactured specimens. However, the scatter was very large.

- The carbonation coefficient, determined on cores, was on average nearly $40 \%$ higher than that determined on separately manufactured specimens, 
whereby it should be noted that this could be only investigated on one civil engineering construction.

Above all, the compressive strength, determined on cores, showed a systematic influence of the environmental temperature. Higher temperatures (approx. $15{ }^{\circ} \mathrm{C}$ and more) led in most cases to lower 28day compressive strength than lower temperatures $(<5$ ${ }^{\circ} \mathrm{C}$ ). The durability properties did not show such a systematic influence. Therefore, it can be concluded that other relevant influences (e.g. curing) were present. The influence of the temperature depends strongly on the binder (cement), too. This means that other binders could result in larger or lesser influence from the environmental temperature.

The scatter of the concrete properties, determined on separately manufactured specimens, was similar for all civil engineering constructions and comparable to that of the cores.

For all hardened concrete properties, determined on cores from structural members, an improvement took place with increasing age (28 days $\rightarrow$ approx. $3 / 4$ year), whereby the compressive strength increased by $20 \%$ and the chloride, carbonation and freeze thaw resistance with de-icing salts increased by approx. $30 \%$.

The non-destructive testing with the rebound hammer gave few reliable results. No general relationship between the durability properties and the non-destructive air permeability tests could be found. It can be only stated that an air permeability (geometric mean) of less than $0.1 \times 10^{-16} \mathrm{~m}^{2}$ should be aimed at to obtain a sufficient concrete durability.

For concrete type testing TT-2 (cores from structural members, tested at 28 days) no limiting values other than the actual guidance values can be proposed due to a lack of data. There were insufficient results available to quantify the quality differences between cores from structural members and separately manufactured specimens. For concrete type testing TT-3 (cores from structural members, tested at $>28$ days) the guidance values from TT-2 can be used. Since the influence of the concrete composition on the durability properties is known, limiting values can be fixed for each site for TT2 and TT-3 testing.

The limiting value (tab. 2) for the chloride migration for XD3 exposure and TT-1 testing (separately manufactured specimens tested at 28 days) in SN EN 206 should be reduced in some cases from $10 \times 10^{-12}$ to 7 $\mathrm{x} 10^{-12} \mathrm{~m}^{2} / \mathrm{s}$ to cover the difference in concrete quality between structural members and separately manufactured specimens.

The limiting values for carbonation for $\mathrm{XC} 3 / \mathrm{XC} 4$ exposure and freeze thaw with de-icing salt resistance for XF4 exposure in SN EN 206 for TT-1 testing (separately manufactured specimens, tested at 28 days, tab. 2) are appropriate.

The difference in the compressive strength between separately manufactured specimens and cores from structural members can be larger than $15 \%$ (SN EN 13791), even when all involved persons made a good job according to the requirements of the standard. This should be kept in mind when results from core tests are analysed.
It is recommended to the owner for civil engineering works that,

- tests should be only performed by well known (accredited) laboratories.

- the results from fresh and hardened concrete tests from the supplier of the concrete should be requested and evaluated.

- acceptance criteria for fresh concrete tests should be fixed and applied

- the results from fresh concrete tests (flow table or slump test, air content and density without filling frame, water content) of the actual building project should be promptly evaluated to obtain information on the concrete properties.

- to tender tests according to TT-1 (separately manufactured specimens) and, whenever possible, according to TT-2 (cores from structural members) to know the difference in concrete quality between structural members and separately manufactured specimens. TT-2 testing should be performed, whenever possible, on cores with a diameter of 100 $\mathrm{mm}$ (not $50 \mathrm{~mm}$ ).

- the curing lasts at least 7 days, at temperatures $>15$ ${ }^{\circ} \mathrm{C}$, too (extension compared to Tab. 23a of SIA 262), in order not to impair concrete quality.

\section{References}

1. F. Jacobs, A. Leemann, VSS report 615, Concrete properties according to SN EN 206-1 (in German) (2007), can be downloaded from http://www.tfb.ch/de/Publikationen.html

2. F. Jacobs, F. Hunkeler, B. Mühlan, VSS report 665 , Efficiency and testing of curing methods of concrete (in German) (2014); can be downloaded from http://www.tfb.ch/de/Publikationen.html

3. S. M. Gouws, M. G. Alexander, F. Maritz, Concrete Beton, 98, Use of durability index tests for the assessment and control of concrete quality on site (2001)

4. F. Jacobs, F. Hunkeler, B. Mühlan, VSS report, draft, Testing and evaluation of the concrete quality in the construction (in German), to be published 2018; can be downloaded after publication from http://www.tfb.ch/de/Publikationen.html 